Resenha 



\section{Garotas mortas (2018), de Selva Almada}

Renata Farias de Felippe

Universidade Federal de Santa Maria

ALMADA, Selva. Garotas mortas. Trad. Sérgio Molina. São Paulo: Todavia, 2018.

Ainda que o título Garotas mortas (2018) - Chicas muertas $(2014)^{1}$, na versão original - possa sugerir uma narrativa ligada ao horror, o romance da escritora argentina Selva Almada retoma a tradição do romance-reportagem, ou ainda, como a própria ficha catalográfica da edição brasileira informa, do denominado romance "não-ficcional". Designação problemática a partir da perspectiva dos estudos literários, a classificação estabelece com o receptor um pacto de leitura explícito, pretensamente circunscrito à veracidade e que confere ao romance uma aura de "legitimidade". A discussão sobre gêneros e rótulos, no entanto, não é o tópico dessa exposição, mas a abordagem de uma das potências que singularizam as narrativas que são apresentadas (ou que se apresentam) como não-ficcionais. Tais narrativas, a partir de ângulos direcionados a segmentos específicos, oportunizam uma análise mais abrangente, dirigida às complexidades e irresoluções sociais. Nesse sentido, o retorno das manifestações do gênero parece oportuno em momentos de profunda crise política e institucional.

Originalmente publicado em 2014, pouco antes do surgimento do movimento Ni una a menos - cuja marcha, realizada em Buenos Aires em 3 de junho de 2015, mobilizou 300.000 pessoas -, a volta do gênero romance-reportagem, ensaiada por Garotas mortas, parece providencial. Narrativa cujo ponto de partida são três casos de feminicídio ocorridos na província de Entre Ríos (local de origem da própria escritora) ${ }^{2}$, na década de 80, período de redemocratização no país, o romance de Almada entre-

1 Originalmente publicado pela filial argentina da editora Random House, em 2014. Neste trabalho, as citações em espanhol, incluídas nas notas de rodapé, foram retiradas dessa edição, no formato e-book. Nesta versão, não há numeração das páginas.

2 A sugestão do caráter autobiográfico aparece na narrativa através das referências aos locais de nascimento e de formação universitária de Selva Almada. Ainda assim, evitamos denominar o romance como autobiográfico pelo fato de o pacto conceituado por Lejeune não ser explícito. 
laça a violência de gênero às tensões políticas e à memória pessoal. Ainda irresolvidos, os casos investigados pela narradora-personagem não só a impulsionam à escrita como estão também relacionados à sua própria vivência, à sua memória, à sua construção como mulher e como escritora:

Estamos no verão e faz calor, quase tanto quanto naquela manhã de 1986, quando, de certo modo, esse livro começou a ser escrito, quando a garota morta atravessou o meu caminho. Agora estou com quarenta anos e, diferentemente dela e

Renata Farias de Felippe dos milhares de mulheres assassinadas em nosso país de lá para cá, continuo viva. Apenas uma questão de sorte ${ }^{3}$ (ALMADA, 2018, p.121, grifos nossos).

O primeiro caso explorado pela narrativa, o assassinato de Andrea Danne, jovem de 19 anos apunhalada em sua própria cama em 1986, revela à narradora-personagem, ainda adolescente, uma dura realidade: que violência pode partir de familiares (ou companheiros) e que o assassinato pode adentrar as portas do que enxergamos como "lar":

\begin{abstract}
Eu tinha treze anos e, naquela manhã, a notícia da garota morta me chegou como uma revelação. Minha casa, a casa de qualquer adolescente, não era o lugar mais seguro do mundo. Você podia ser morta dentro da sua própria casa. 0 horror podia viver sob o mesmo teto ${ }^{4}$ (ALMADA, p. 12, grifos nossos).
\end{abstract}

O horror, que é sugerido pela narrativa em seu título, portanto, aparece ligado à possibilidade de as agressões partirem de pessoas próximas, com as quais a personagem (e, por extensão, todas as jovens mulheres que aquela representa) convive. No decorrer do romance, no entanto, a morte de Andrea Danne representa apenas o início de um duro aprendizado, que se estenderá à idade adulta da narradora-personagem e que lhe ensinará o sentido da palavra feminicídio.

3 "Estamos en verano y hace calor, casi como aquella mañana del 16 de noviembre de 1986 cuando, en cierto modo, empezó a escribirse este libro, cuando la chica muerta se cruzó en mi camino. Ahora tengo cuarenta años y, a diferencia de ella y de las miles de mujeres asesinadas en nuestro país desde entonces, sigo viva. Solo una cuestión de suerte"

4 "Yo tenía trece años y a esa mañana, la noticia e la chica muerta me llegó como una revelación. Mi casa, la casa de cualquier adolescente, no era el lugar más seguro del mundo. Dentro de tu casa podían matarte. El horror podía vivir bajo el mismo techo que vos". 
Durante mais de vinte anos, Andrea esteve por perto. Voltava de quando em quando com a notícia de outra mulher morta. Iam se acumulando os nomes que apareciam a conta-gotas nas manchetes de jornais de circulação nacional: María Soledad Morales, Gladys McDonald, Elena Arreche, Adriana e Cecilia Barreda, Liliana Tallarico, Ana Fuschini, Sandra Reitier, Carolina Aló, Natalia Melman, Fabiana Gandiaga, María Marta García Belsunce, Marela Martínez, Paulina Lebbos, Nora Dalmasso, Rosana Galliano. Cada uma delas me levava a pensar em Andrea e em seu assassinato impune [...].

Três adolescentes do interior assassinadas nos anos 80, três mortes impunes ocorridas quando em nosso país ainda se ignorava o termo feminicídio. [...]. Eu não sabia que uma mulher

\section{Garotas}

mortas (2018),

de Selva

Almada

375

podia ser morta pelo simples fato de ser mulher, mas tinha escutado histórias que com o tempo fui ligando umas às outras.

Casos que não terminavam com a morte da mulher, mas em que ela era objeto da misoginia, do abuso, do desprezo ${ }^{5}$ (ALMADA, 2018, p. 12-13, grifos nossos).

As passagens, atentas a uma tragédia social que é gendrificada, chamam a atenção para a individualidade das vidas ceifadas, de mulheres dotadas de nome e sobrenome. Cada um dos assassinatos lembra à narradora o acontecimento primeiro, o emblemático caso Andrea Danne, que marcou a sua biografia por lhe apresentar a própria vulnerabilidade e suscetibilidade. Por outro lado, quando enumerados, os casos de feminicídio mencionados sugerem uma incômoda sobreposição e banalização. A mesma estratégia enumerativa é adotada por Almada no Epílogo, quando a narradora revela a ocorrência de dez feminicídios em um único mês na Argentina (especificamente, em janeiro de 2014):

5 “Durante más de veinte años Andrea estuvo cerca. Volvía cada tanto con la noticia de otra mujer muerta. Los nombres que, en cuentagotas, llegaban a la primera plana de los diarios de circulación nacional se iban sumando: María Soledad Morales, Gladys Mc Donald, Elena Arreche, [...]. Cada una de ellas me hacía pensar en Andrea y su asesinato impune [...].

Tres adolescentes de provincia asesinadas en los años ochenta, tres muertes impunes ocurridas cuando todavía, en nuestro país, desconocíamos el término femicidio. [...]. No sabía que a una mujer podían matarla por el solo hecho de ser mujer, pero había escuchado historias que, con el tiempo, fui hilvanando. Anécdotas que no habían terminado en la muerte de la mujer, pero que sí habían hecho de ella objeto de la misoginia, del abuso, del desprecio". 
Faz um mês que o ano começou. Pelo menos dez mulheres foram assassinadas por serem mulheres. Digo pelo menos porque são os nomes que apareceram nos jornais, daquelas que viraram notícia. Mariella Bustos, assassinada com vinte e duas facadas em Las Caleras, província de Córdoba. Marina Soledad da Silva, espancada e atirada em um poço, em Nemesio Parma, província de Misiones. Zulma Brochero, de uma estocada na testa, e Arnulfa Ríos, de um tiro, ambas em Río Segundo, Córdoba. Paola Tomé, estrangulada, em Junín, província de Buenos Aires. Priscila Lafuente, espanca-

Renata Farias de Felippe

da, meio queimada em uma churrasqueira e atirada num córrego, em Berazategui, Grande Buenos Aires. Carolina Arcos, de uma pancada na cabeça, numa construção, em Rafaela, província de Santa Fe. Nanci Molina, esfaqueada, em Presidencia de La Plaza, província do Chaco. Luciana Rodríguez, espancada, em Mendoza, capital. Querlinda Vásquez, estrangulada em Las Heras, província de Santa Cruz $^{6}$ (ALMADA, 2018, p. 121).

Diversas vítimas de diferentes localidades do país, cruelmente assassinadas de diferentes maneiras: tragédias sobrepostas que apontam para a violência endêmica, contínua, arraigada. Meramente citados e provavelmente irresolvidos, os assassinatos de janeiro de 2014, como aqueles que, nos anos 1980 intrigaram a jovem narradora e a escritora adulta, representam os casos mais extremos de violência contra as mulheres, mas uma série de acontecimentos desconcertantes - os imensuráveis casos de misoginia, desprezo, abuso, exploração e descaso institucional - são também abordados em Garotas mortas:

Ela [uma conterrânea da narradora] saiu do baile com uma amiga. [...]. A amiga entrou em casa, ela seguiu em frente, sossega$\mathrm{da},[\ldots]$, num lugar onde nunca acontecia nada. Eles a agarraram no escuro e a espancaram, os dois a penetraram várias vezes, se

\footnotetext{
6 "Hace un mes que comenzó el año. Al menos diez mujeres fueron asesinadas por ser mujeres. Digo al menos porque estos son los nombres que salieron en los diarios, las que fueron noticia.

Mariela Bustos asesinada de 22 puñaladas en Las Caleras, Córdoba. Marina Soledad Da Silva, a golpes y arrojada a un pozo, en Nemesio Parma, Misiones. Zulma Brochero, de un puntazo en la frente, y Arnulfa Ríos, de un disparo, ambas em Río Segundo, Córdoba. Paola Tomé, estrangulada, en Junín, Buenos Aires. Priscila Lafuente, a golpes, medio quemada en una parrilla y luego arrojada a un arroyo, em Berazategui. Carolina Arcos, de un golpe en la cabeza, en una obra en construcción, en Rafaela, Santa Fe. Nanci Molina, apuñalada, en Presidencia de la Plaza, Chaco. Luciana Rodríguez, a golpes, en Mendoza capital. Querlinda Vásquez, estrangulada,en Las Heras, Santa Cruz".
} 
revezando. E quando até as picas se enfastiaram, continuaram a violentá-la com uma garrafa (ALMADA, 2018, p. 14).

Os rapazes tinham um hábito, um jogo, [...]. Eles marcavam uma garota, sempre de classe baixa. Um dos rapazes da turma a paquerava. Seguia a menina pela rua e lhe dizia coisas sedutoras, como se quisesse namorar com ela. [...]. Quando a moça cedia, vinha o convite para o baile. [...]. Nunca chegavam ao baile. $\mathrm{O}$ carro se desviava para o balneário ou algum lugar deserto. $\mathrm{O}$ resto da turma já estava esperando lá, e a garota era obrigada a ir com todos, ou melhor, ia passando de mão em mão (ALMADA, 2018, p. 12-13, grifos nossos).

\author{
Garotas \\ mortas (2018), \\ de Selva \\ Almada
}

Visitar um homem sozinho que, em troca, ajuda com dinheiro, é uma forma de prostituição naturalizada no interior. Assim como a da empregada doméstica que fora do trabalho se encontra com o marido da patroa, e esses encontros engordam um pouco o salário. Eu vi acontecer isso com moças da minha família quando era pequena (ALMADA, 2018, p. 39 grifo nosso).

Passados dez anos, Sara [mãe de Sarita Mundín] tomou conhecimento de uma nova técnica que permitia reconhecer a identidade de restos humanos, [...]: o exame de DNA. [...]. Dela, colheram sangue. O resultado deu negativo. [...]. [...], e só então percebo que há outra mulher morta que ninguém reclama ou pela qual a família também está procurando [...] $]^{\top}$ (ALMADA, 2018, p. 85, grifo nosso).

7 "Ella se fue del baile con una amiga. [...]. La amiga se quedó primera, ella siguió, tranquila, [...], en un pueblo donde nunca pasaba nada. La interceptaron en la oscuridad, la golpearon, le entraron los dos, cada uno a su turno, varias veces. Y cuando hasta las vergas se asquearon, la siguieron violando con una botella. Los muchachos tenían una costumbre, un juego, [...]. Le decían hacer un becerro. Marcaban a una chica, siempre de clase baja. Uno del grupo le hacía el novio. La seguía en la calle, le decía cosas, la seducía [...]. Una vez que la muchacha cedía, venía la invitación al baile del sábado [...]. Nunca llegaban al baile. El auto se desviaba para el balneario o para algún lugar solitario. Allí esperaba el resto de la barra y la chica tenía que pasar con todos. Mejor dicho, se la pasaban de mano en mano.

Visitar a un hombre solo que a cambio ayuda con plata es una forma de prostitución que está naturalizada en los pueblos del interior. Como la de la empleada doméstica que fuera del trabajo se encuentra con el marido de la patrona y esos encuentros le arriman unos pesos más al sueldo. Lo he visto en muchachas de mi familia, cuando era chica.

Diez años después, Sara se enteró de un nuevo estudio que permitía reconocer la identidad de restos humanos, aunque fueran solo huesos: el ADN. [...]. A ella le sacaron sangre. El resultado dio negativo. [...]. [...], y entonces caigo en la cuenta de que hay otra mujer muerta por la que nadie reclama o a la que todavía su familia la sigue buscando [...]". 
Incomodamente familiares às leitoras e aos leitores, os acontecimentos tratados por Almada são abordados de forma direta, por vezes, áspera, escolha que abala o leitor e que parece em acordo com o pacto de veracidade implicado ao romance não-ficcional. Predominante na narrativa, a abordagem sem subterfúgios é também utilizada para tratar os atos daquelas que conseguiram reagir às agressões e às ameaças, entre elas, mulheres da família da narradora-personagem:

Quando eu era pequena, minha mãe me contou a mesma histó-

Renata Farias de Felippe

ria várias vezes. Era um episódio que aconteceu pouco depois de ela se casar com o meu pai. [...]. Pouco depois de começarem a viver juntos, durante o almoço, os dois se pegaram numa discussão, [...]. Até que a certa altura meu pai levantou uma das mãos, ameaçando acertar um tapa na minha mãe. Ela, sem pensar duas vezes, cravou um garfo no braço que ele tinha apoiado na mesa. Meu pai nunca mais bancou o valentão ${ }^{8}$ (ALMADA, 2018, p. 35).

Episódio aparentemente banal da biografia familiar, a investida paterna reitera um dos temores que atravessam a juventude da narradora e que é revelado já no começo da narrativa: o de que a própria casa não é um lugar seguro, principalmente, às mulheres jovens. Despertado na narradora-personagem após o assassinato de Andrea Danne, o medo é potencializado diante da constatação de que a violência extrema pode partir de pessoas próximas, daquelas em quem confiamos. De acordo com Almada, ao contrário do que nos foi ensinado, o "horror", sugerido no título do romance, pode "viver sob o mesmo teto" (p. 12).

\begin{abstract}
Desde pequenas nos ensinavam que não devíamos falar com estranhos e que devíamos tomar cuidado com o Tarado. 0 Tarado era uma entidade tão mágica quanto, [...], La Solapa e o Homem do Saco. Era quem podia te violentar [sic.] se você andasse sozinha tarde da noite ou se aventurasse por lugares desertos. [...].
\end{abstract} Nunca ninguém falou que você podia ser estuprada pelo ma-

\footnotetext{
8 "De chica, mi madre me contó en varias ocasiones la misma anécdota. Una de cuando recién se habían casado con mi padre. [...]. Al poco tiempo de vivir juntos, mientras almorzaban, tuvieron una discusión, [...]. Entonces mi padre levanto una de sus manos, amagándole una cachetada. Y mi madre, ni lerda ni perezosa, le clavó un tenedor en el brazo que él tenía apoyado en la mesa. Mi padre nunca más se hizo el guapo".
} 
rido, pelo pai, pelo irmão, pelo vizinho, pelo professor. Por um homem em quem você tem toda a confiança' (ALMADA, 2018, p. 36-37, grifo nosso).

A tentativa de estupro sofrida por uma das tias da narradora, perpetrada por um primo, revela que a misoginia ronda a organização familiar e que resistir a ela para, por fim, combatê-la, envolvem esforços além das ações da vítima. Banir a violência sexual no âmbito familiar é algo que, na narrativa, pode também ser "resolvido" em família, ainda que por meios controversos, como revela o Epílogo do romance:

[...] Tatu era um primo quarentão que já fazia tempo que a comia com os olhos [...]. Ai cara, que susto!, minha tia falou, e foi seguindo o seu caminho. Mas ele não respondeu e a segurou por um braço, [...]. Queria arrastá-la para o fundo do milharal [...]. Minha tia era miudinha. Ela nunca entendeu de onde tirou tamanha força para se safar das mãos rudes que prendiam seus braços [...]. Correu tanto que pensou que ia rebentar, como os cavalos.

Nunca tive tanto medo e nunca tive tanta coragem como dessa vez, disse. [...]. Depois meu avô deu uma surra no Tatu, e ele nunca mais voltou a se engraçar com minha tia, e tomara que com nenhuma outra moça ${ }^{10}$ (ALMADA, 2018, p. 124, grifos nossos).

Garotas mortas está pontuado por reações isoladas de mulheres às violências cotidianas, situações que são tratadas pela narradora como se embaladas pela "música de uma pequena vitória" (p. 124). Entre as reações abordadas pela narradora está a de uma menina “de uns doze

9 "Desde chicas nos enseñaban que no debíamos hablar con extraños y que debíamos cuidarnos del Sátiro. El Sátiro era una entidade tan mágica como, [...] la Solapa o el Viejo de la Bolsa. Era el que podía violarte si andabas sola a deshora o si te aventurabas por sitios desolados [...]. Nunca nos dijeron que podía violarte tu marido, tu papá, tu hermano, tu primo, tu vecino, tu abuelo, tu maestro. Un varón en el que depositaras toda tu confianza".

10 “[...] el Tatú, un primo cuarentón que hacía tiempo se la venía comiendo con los ojos [...]. Qué hacés, chambón, me asustaste, le dijo la tía amagando seguir su ruta. Pero él no le contestó nada y le manoteó un brazo, [...]. Se la quería llevar adentro del maizal [...]. La tía era una muchacha menuda. Nunca se explicó de dónde sacó la fuerza necesaria para zafarse de las manos toscas que se cerraban sobre sus brazos [...]. Corrió tanto que pensó que iba a reventar, como los caballos.

Nunca tuve tanto miedo y nunca tuve tanto valor como esa vez, me dijo [...]. Después el abuelo le dio una paliza al Tatú y él nunca volvió a acercarse a la tía y ojalá que a ninguna otra muchacha". 
Renata Farias de Felippe

anos, [...] morena, magrinha, seguida por um séquito de molequinhos mais ou menos de sua idade", que "briga aos gritos com um grupinho de meninos [...]. Uma molequinha carnavalesca encrenqueira. Uma menina sozinha numa noite de Carnaval" (p. 56). A fragilidade e a solidão da menina, numa noite em que os excessos são tolerados, não são suficientes para calá-la. Significativa, a ruidosa reação solitária da adolescente parece prognóstica, à semelhança da origem despretensiosa do movimento conhecido como Ni una a menos, cuja movimentação tem, hoje, grande impacto e contundência na sociedade argentina.

Um ano após a publicação de Chicas muertas, uma maratona de leituras realizada em praça pública, ocorrida em Buenos Aires, mobilizou um grupo determinado a denunciar e a discutir o feminicídio bem como a violência, efetiva e simbólica, contra as mulheres. Meses após o ato, o assassinato da jovem Chiara Paéz leva o grupo inicial a convocar uma manifestação diante do Congresso argentino, protesto que reuniu cerca de 300.000 pessoas e que, posteriormente, seria replicado em várias cidades do país. Quando analisado em retrospecto, portanto, o romance não-ficcional de Almada parece anunciar um sentimento generalizado de indignação que tomaria imensas proporções. Nesse sentido, o retorno do romance reportagem, ensaiado pelo surgimento da narrativa, parece providencial.

Se em Garotas mortas a linguagem econômica, precisa, e a citação de dezenas de nomes de vítimas de feminicídio são asperezas que provocam incômodo, a estratégia utilizada pela autora, de inserir uma personagem cartomante, intermediária entre as interrogações da narradora-consulente e o mundo das mortas (Andrea Danne, Maria Luísa Quevedo e Sarita Mundín), parece colocar em suspenso o pacto de veracidade implicado ao gênero. São também nas breves passagens em que a Senhora e a narradora interagem que a narrativa assume sentidos explicitamente conotativos e caráter sensibilizante, como no momento em que a cartomante conta à investigadora a fábula de La Huesera, a Mulher dos Ossos:

É uma velha muito velha, que vive em certo esconderijo da alma. [...]. Sua tarefa consiste em catar ossos. Ela recolhe e guarda tudo aquilo que periga se perder [...]. De volta à sua choupana com uma braçada de ossos, ela monta o esqueleto [...]. À medida que canta, os ossos vão se forrando de carne [...]. Ela continua a cantar, e a criatura ganha vida [...]. 
Talvez seja esta a sua missão [da narradora-personagem-escritora]: recolher os ossos das garotas, armá-las, dar-lhes voz e depois deixá-las correr livremente para onde tiverem que ir $^{11}$ (ALMADA, 2018, p. 33-4).

A história contada pela Senhora, além de promover a suspensão do pacto citado, revela o caráter visibilizador da escrita, manifesta a importância da palavra no intuito de retirar as vítimas do silêncio e do anonimato. Através do conto, a fala da cartomante expõe a relevância das fabulações na busca de uma verdade, gesto que é repetido por Almada: diante do descaso das instituições, das imprecisões da imprensa oitentista e das interrogações das famílias das vítimas em relação aos crimes, a inserção da personagem pitonisa, mediadora entre mundos,

Garotas mortas (2018), de Selva Almada

\begin{abstract}
Ontem me despedi da Senhora. [...]. Ela me disse que já é hora de largar, que não é bom andar muito tempo vagando de um lado para outro, da vida para a morte. Que as garotas devem voltar para o lugar a que agora pertencem.

Ela me disse isso pegando na minha mão por cima da mesinha que nos separava. [...]. Eu também sempre apertei sua mão, e aí ela começou a me largar lentamente. Segurei um pouco, mais um momento, ainda podia sentir as garotas através dela. Olhou para mim. Ou elas me olharam, e compreendi e também comecei a largar.
\end{abstract}

Três velas brancas. Meu adeus às garotas.

11 "Es una vieja muy vieja que vive en algún escondite del alma [...]. Su tarea consiste en recoger huesos. Junta y guarda todo lo que corre el peligro de perderse [...]. De vuelta en su choza, con la brazada de huesos, arma el esqueleto [...]. A medida que canta, los huesos se van cubriendo de carne [...]. Ella sigue cantando y la criatura cobra vida [...].

Tal vez esa sea tu misión: juntar los huesos de las chicas, armarlas, darles voz y después dejarlas correr libremente hacia donde sea que tengan que ir". 
Uma vela branca para Andrea. Uma vela branca para María Luisa. Uma vela branca para Sarita, [...]. Um mesmo desejo a todas: que descansem ${ }^{12}$ (p. 122).

Melancólico, o desfecho da investigação empreendida pela narradora esbarra na irresolução. Às três vítimas de feminicídio, cujas mortes estão entrelaçadas à vivência e à memória da personagem narradora, a única justiça que pode ser feita é o próprio romance Garotas mortas, narrativa que, mesmo sob a denominação "não-ficcional", faz

Renata Farias de Felippe justiça literária às três mulheres. Assim, o livro de Almada pode ser visto como a materialização da "música de uma pequena vitória", melodia que o encerra, mas que, em retrospecto, soma-se ao brado de uma numerosa sinfonia.

12 "Ayer me despedí de la Señora [...]. Me dijo que ya es hora de soltar, que no es bueno andar mucho tempo vagando de un lado al otro, de la vida a la muerte. Que las chicas deben volver allí adonde pertenecen ahora. Me lo dijo tomándome la mano por encima de la mesita que nos separaba [...]. Yo también apreté su mano y entonces empezó a soltarme despacito. Me agarré um poco, un momento más, todavía podía sentir a las chicas a través de ella. Me miró. o ellas me miraron y comprendí y también empecé a soltar.

Tres velas blancas. Mi adiós a las chicas.

Una vela blanca para Andrea. Una vela blanca para María Luisa. Una vela blanca para Sarita [...]. Un mismo deseo para todas: que descansen". 